\title{
Botulinum toxin treatment for essential palatal tremors presenting with nasal clicks instead of pulsatile tinnitus: a case report
}

\author{
Yufeng Ye, Shiyu Liao, Baozhen Luo and Liyan Ni*
}

\begin{abstract}
Background: In this study, we report a rare case of an adult patient with essential palatal tremors (EPT) presenting as nasal clicks, instead of otic clicks or objective pulsatile tinnitus in common EPT.

Case presentation: Nasal endoscopic examination and EMG recordings of the soft palate muscles were performed to confirm the source of the clicks. Initial treatment with lidocaine provided symptomatic relief for four hours. The patient was then treated with four simultaneous injections of $12.5 \mathrm{U}$ of botulinum toxin in four different sites of the soft palate. Palatal tremors and clicks completely disappeared within three months of treatment.

Conclusions: To our knowledge, this is the first case of EPT that presented with nasal clicks. We recommend that otolaryngologists should expect this rare occurrence in the clinical setting, and handle patients presenting with such symptoms with care and compassion in order not to worsen their psychological status.
\end{abstract}

Keywords: Case report, Palatal tremors, Botulinum toxin, Inferior olive, Pulsatile tinnitus, Electromyography

\section{Background}

Palatal tremor i.s a rare movement disorder characterized by continuous rhythmic jerks of the soft palate that are often perceived as tinnitus [1]. Palatal tremors are classified as symptomatic palatal tremors (SPTs) and essential palatal tremors (EPTs). SPTs mainly present with neurological deficits such as dysarthria, nystagmus and ataxia. Abnormalities in the function of the nucleus dentatus, nucleus ruber and/or inferior olivary complex are known to contribute to the pathophysiology of SPT [2, 3]. SPTs rarely present with ear clicks and palatal movements, while EPTs almost exclusively present with ear clicks and palatal movements. Excessive contraction of the tensor veli palatini (TVP) muscle, which is innervated by the trigeminal nerve, is thought to be the cause of EPTs. According to the diagnostic criteria proposed by Deuschl et a1. $[3,4]$, no intracranial pathology is associated with EPTs. Patients have normal cerebellar function and pendular nystagmus. Furthermore, throat muscle involvement is not expected. In the literature,

\footnotetext{
* Correspondence: nily2001@126.com

ENT Department, The Second Affiliated Hospital \& Yuying Children's Hospital of Wenzhou Medical University, 109 Xueyuan Western Road, Wenzhou, Zhejiang Province, People's Republic of China
}

several cases of EPT associated with psychogenic factors, as well as those of unknown etiology, have been reported $[5,6]$.

Regardless of etiology, EPTs usually present with objective tinnitus of otic origin or ear clicks. However, EPTs with nasal clicks have hitherto not been reported. Here, we report the case of an adult patient with EPT presenting as nasal clicks who was effectively treated with botulinum toxin injection.

\section{Case presentation \\ Patient history}

A previously healthy 51-year-old man presented at our hospital with a chief complaint of clicking sounds heard in the nose. He mentioned that the noise was audible to others and disappeared during sleep. He had excessive phlegm for two years and pharyngalgia for one week. His birth, growth and developmental history were all normal. He had no history of head trauma, chronic ear disease, or neurological disorder. None of his family members had a history of nasal clicks or tinnitus. The patient had been very uncomfortable due to the persistent sound. 


\section{Physical examination and preliminary diagnosis}

An otolaryngologist performed physical examination of the nose, mouth and pharynx; and found that the audible "clicking" noise originated from the nose (Additional file 1: Video S1). No anomaly other than a fast rhythmic tremor of the soft palate was observed upon physical examination. Other muscles in the pharynx, mouth and eyes did not seem to be involved based on these examinations. Results of audiometry, tympanometry and neurologic examinations including cranial magnetic resonance imaging (MRI) and neurological physical examinations were all normal. Rhythmic palatal movements produced a high-pitched "clicking" sound with a frequency of approximately 100 clicks per minute (Additional file 1: Video S1, Additional file 2: Video S2 and Additional file 3: Video S3). The examiner could clearly hear the sound at a distance of $10 \mathrm{~cm}$ from the nasal tip. When the patient was asked to tilt his neck slightly backward, the noise was reduced (Additional file 4: Video S4).

Laboratory results including routine blood work, antinuclear antibody analysis, thyroid tests, and hepatic and renal functions tests were all normal (Table 1). Computed tomography (CT) scans of the brain and cervical region did not show any abnormalities. A nasal sinus $\mathrm{CT}$ scan revealed fungal maxillary sinusitis on the left side (Fig. 1), which was treated by functional endoscopic sinus surgery. No signs of olivary nucleus hypertrophy or occupying lesions of the skull base were visible on MRI scans (Fig. 2).

\section{Nasal endoscopic examination and sinus surgery}

We then performed a nasal endoscopic examination. Involuntary rhythmic movements of the nasopharyngeal lateral wall or muscles surrounding the eustachian tube were not observed (Additional file 2: Video S2 and Additional file 3: Video S3). However, the torus tubarius was found to be involved. We identified the source of the clicks on the basis of the adjacency of the sound to the nose and throat. Thus, the nasal cavity was confirmed as the source of the sound.

Endoscopic sinus surgery was performed to open the left maxillary sinus. The patient was placed in the supine position. After endotracheal intubation and routine disinfection, sterile drapes were placed and the operation commenced. An adrenaline cotton sheet was placed in the left nasal mucosa to absorb nasal secretions. The middle turbinate root, agger and uncinate process of the left side were locally anesthetized by injecting lidocainecontaining adrenaline. Under $0^{\circ}$ endoscopy, the left uncinate process was lifted by a nasal probe, and the tail section of the uncinate process was separated. The upper and lower ends of the uncinate process adjacent to the lateral nasal wall were excised with a curved scissor. The separated uncinate process was removed with an ethmoidal sinus forcep. Thereafter, the bone at the tail end of the uncinate process was removed with a detacher and the anterior fontanelle was removed with a back biting rongeur. Thus, the natural orifice of the maxillary sinus was expanded. The maxillary sinus observed with $70^{\circ}$ endoscopy revealed several brown bean-curd-residue-like lesions. A subsequent pathological examination confirmed that they were mould clumps. We cleaned the lesions, flushed the maxillary sinus cavity with saline via a curved suction tube, and ensured that the sinus mucosa was smooth and without any residual lesions. The left nasal cavity was filled with one expansion sponge, and the operation was completed.

However, the "clicking" noise did not stop. In a followup exam three months after surgery, we confirmed that the ostium of the left maxillary sinus had significantly opened up, and the sinus was clean.

\section{Electromyography}

To determine the etiology of the nasal click, we recorded the activities of the soft palatal muscles including the TVP, palatopharyngeus, palatoglossus, levator veli palatini (LVP), and uvularis muscles by direct electromyography (EMG, Fig. 3). All the above-mentioned muscles except the TVP revealed abnormal waveforms. This was a highly unusual finding. The TPV is usually the main muscle associated with EPT. However, our EMG results revealed that all other muscles except the TVP were causing these contractions.

\section{Treatment}

The nasal clicks significantly affected the patient's social life. The patient did not receive any other treatment from other hospitals before he arrived at our hospital. To explore whether blocking nerve impulse conduction can weaken or eliminate the tremors, we first injected $0.5 \mathrm{~mL}$ of $2 \%$ lidocaine into the palatal muscles including the palatopharyngeus, palatoglossus, LVP and uvularis muscles. Palatal tremors disappeared, but returned within four hours given that the effective time of lidocaine anesthesia is approximately $1.5 \mathrm{~h}$. When the patient visited our hospital a week later, we modified the treatment strategy. Botulinum toxin was injected into four different regions (dose, $12.5 \mathrm{U} /$ site) of the soft palatine (Fig. 4). The patient tolerated the injections well on the first day. On the second day, the patient experienced dragging pain, and his tongue twisted involuntarily when he had to open his mouth wide. Two weeks later, the pain subsided, and his lisp disappeared. The patient did not complain of excessive phlegm thereafter. No other side effects such as choking after drinking or difficulty in swallowing were reported. Three months after receiving botulinum toxin injections, the palatal tremors disappeared; and the patient felt well. However, eight 
Table 1 Laboratory results including routine blood work, antinuclear antibody analysis, thyroid tests, and hepatic and renal functions

\begin{tabular}{|c|c|c|c|c|c|c|}
\hline Test name & Abbreviations & Item name & Results & Ref & Unit & OD value \\
\hline \multirow[t]{5}{*}{ Hepatitis B virus } & HBSAG & $\mathrm{HbsAg}$ & 0.688 (Negative) & $<1.000$ & $\mathrm{COI}$ & 0.688 \\
\hline & AHBS & Anti-HBs & 2.00 (Negative) & & $\mathrm{IU} / \mathrm{L}$ & 2.000 \\
\hline & HBEAG & $\mathrm{HbeAg}$ & 0.101 (Negative) & $<1.000$ & $\mathrm{COI}$ & 0.101 \\
\hline & AHBE & Anti-Hbe & 1.56 (Negative) & $>1.000$ & $\mathrm{COI}$ & 1.560 \\
\hline & $\mathrm{AHBC}$ & Anti-HBC & 1.89 (Negative) & $>1.000$ & $\mathrm{COI}$ & 1.890 \\
\hline \multirow[t]{3}{*}{ HIV,HCV,TPHA } & HIV & HIV antibodies (screen) & Negative & Negative & & 0 \\
\hline & $\mathrm{HCV}$ & Anti-HCV & Negative & Negative & & 0 \\
\hline & TPHA & $\begin{array}{l}\text { Treponema pallidum specific } \\
\text { antibody }\end{array}$ & Negative & Negative & & 0 \\
\hline \multirow{20}{*}{$\begin{array}{l}\text { Electrolytes, liver and } \\
\text { kidney function }\end{array}$} & ALT & Glutamic-pyruvic transaminase & 19 & $0 \sim 50$ & $U / L$ & 19.000 \\
\hline & AST & $\begin{array}{l}\text { Glutamic oxalacetic } \\
\text { transaminase }\end{array}$ & 18 & $15 \sim 45$ & $U / L$ & 18.000 \\
\hline & AS/AL & AST/ALT & 0.95 & & & 0.947 \\
\hline & ALP & Alkaline phosphatase & 95 & $45 \sim 125$ & $U / L$ & 95.000 \\
\hline & GGT & Glutamyl transpeptidase & 35 & $10 \sim 60$ & $U / L$ & 35.000 \\
\hline & TP & Total protein & 78.9 & $61.0 \sim 79.0$ & $g / L$ & 78.900 \\
\hline & ALB & Albumin & 44.9 & $34.0 \sim 48.0$ & $g / L$ & 44.900 \\
\hline & GLO & Globulin & 34.0 & $24.8 \sim 38.8$ & $g / L$ & 34.000 \\
\hline & $\mathrm{A} / \mathrm{G}$ & ALB/GLB & 1.3 & $1.2 \sim 2.0$ & & 1.321 \\
\hline & TBIL & Total bilirubin & 10.4 & $6.8 \sim 34.2$ & $\mu \mathrm{mol} / \mathrm{L}$ & 10.400 \\
\hline & DBIL & Direct bilirubin & 1.5 & $1.7 \sim 8.6$ & $\mu \mathrm{mol} / \mathrm{L}$ & 1.500 \\
\hline & IBIL & Indirect bilirubin & 8.9 & $4.8 \sim 25.0$ & $\mu \mathrm{mol} / \mathrm{L}$ & 8.900 \\
\hline & GLU-S & Fasting blood-glucose & 5.53 & $3.90 \sim 6.10$ & $\mathrm{mmol} / \mathrm{L}$ & 5.530 \\
\hline & BUN & Serum urea & 3.82 & $2.90 \sim 8.20$ & $\mathrm{mmol} / \mathrm{L}$ & 3.820 \\
\hline & CREA & Creatinine & 91.2 & $50.0 \sim 133.0$ & $\mu \mathrm{mol} / \mathrm{L}$ & 91.200 \\
\hline & $\mathrm{BU} / \mathrm{CR}$ & Serum urea/Creatinine & 0.042 & $0.03 \sim 0.15$ & & 0.042 \\
\hline & UA & Uric acid & 260 & $149 \sim 416$ & $\mu \mathrm{mol} / \mathrm{L}$ & 260.000 \\
\hline & NA & Sodium & 137.5 & $137.0 \sim 147.0$ & $\mathrm{mmol} / \mathrm{L}$ & 137.500 \\
\hline & K & Kalium & 4.33 & $3.50 \sim 5.30$ & $\mathrm{mmol} / \mathrm{L}$ & 4.330 \\
\hline & $\mathrm{CL}$ & Chlorine & 105.3 & $99.0 \sim 110.0$ & $\mathrm{mmol} / \mathrm{L}$ & 105.300 \\
\hline \multirow[t]{12}{*}{ Routine stool test } & YS & Color & Yellow & & & 0 \\
\hline & $J \mathrm{D}$ & Toughness & Soft & & & 0 \\
\hline & NY & Mucus & Negative & & & 0 \\
\hline & $\mathrm{BXQ}$ & White blood cells (stool) & Negative & & /High power field & 0 \\
\hline & $H X B$ & Red blood cells (stool) & Negative & & /High power field & 0 \\
\hline & NC & Pyocyte & Not found & & /Low power field & 0 \\
\hline & $\mathrm{AMB}$ & Amebic protozoa & Not found & Not found & & 0 \\
\hline & JMJ & Saccharomycopsis & Not found & Not found & & 0 \\
\hline & $\mathrm{HCL}$ & Ova of roundworm & Not found & Not found & & 0 \\
\hline & $N X$ & Purulent blood & Negative & Negative & & 0 \\
\hline & $\mathrm{CL}$ & Ovum & Not found & Not found & & 0 \\
\hline & JSC & Parasite & Not found & & & 0 \\
\hline \multirow[t]{3}{*}{ Urine routines } & COLOR & Color & Faint yellow & & & 2.000 \\
\hline & TURB & Turbidity & Clear & & & 0 \\
\hline & WBC & Leukocyte count & 0.54 & & /High power field & 0.540 \\
\hline
\end{tabular}


Table 1 Laboratory results including routine blood work, antinuclear antibody analysis, thyroid tests, and hepatic and renal functions (Continued)

\begin{tabular}{|c|c|c|c|c|c|c|}
\hline & WBC1 & Leukocyte count & 3.00 & & $/ \mu l$ & 3.002 \\
\hline & $\mathrm{RBC}$ & Erythrocyte count & 1.80 & & /High power field & 1.800 \\
\hline & $\mathrm{RBC1}$ & Erythrocyte count & 10.01 & & $/ \mu l$ & 10.008 \\
\hline & TMGX & Hyaline cast & 2.90 & & /Low power field & 2.900 \\
\hline & WFLGX & Granular casts & Negative & Negative & /Low power field & -2.900 \\
\hline & CG & Cellular cast & Negative & Negative & /Low power field & -2.900 \\
\hline & LZSP & Squamous epithelial cell & 5.80 & & /Low power field & 2.000 \\
\hline & BLD & Urine occult blood & Weakly positive $( \pm)$ & Negative & & 0 \\
\hline & BIL & Urine bilirubin & Negative & Negative & & 0 \\
\hline & URO & Urobilinogen & Negative & Negative & & 0 \\
\hline & KET & Urine acetone bodies & Negative & Negative & & 0 \\
\hline & PRO & $\begin{array}{l}\text { Qualitative test of urinary } \\
\text { protein }\end{array}$ & Weakly positive $( \pm)$ & Negative & & 0 \\
\hline & SG & Urine specific gravity & 1.019 & $1.003 \sim 1.03$ & & 1.019 \\
\hline & NIT & Nitrite & Negative & Negative & & 0 \\
\hline & GLU & Urine sugar & Negative & Negative & & 0 \\
\hline & $\mathrm{PH}$ & $\mathrm{pH}$ & 7.0 & $4.6 \sim 8$ & & 7.000 \\
\hline & LEU & Neutrophil esterase & Negative & Negative & & 0 \\
\hline Blood coagulation & PT & Prothrombin time & 12.00 & $12.00 \sim 15.00$ & Second & 12.000 \\
\hline & PTS-CP & Normal controls (PT) & 12.50 & & Second & 12.500 \\
\hline & INR & International normalized ratio & 0.95 & $0.85 \sim 1.15$ & & 0.950 \\
\hline & APTT & $\begin{array}{l}\text { Activated partial } \\
\text { thromboplastin time }\end{array}$ & 32.10 & $30.00 \sim 45.00$ & Second & 32.100 \\
\hline & APTTS- & Normal controls (APTT) & 35.00 & & Second & 35.000 \\
\hline & $\pi$ & Thrombin time & 16.30 & $14.00 \sim 18.00$ & Second & 16.300 \\
\hline & $\mathrm{FIB}$ & Fibrinogen & 2.95 & $2.00 \sim 4.00$ & $g / L$ & 2.950 \\
\hline & $\mathrm{BBBC}$ & Sample preservation & $\begin{array}{l}\text { The sample retained } \\
\text { for three days }\end{array}$ & & & 1.000 \\
\hline Blood routine & WBC & Leukocyte count & 7.00 & $4 \sim 10$ & $\times 10^{\wedge} 9 / \mathrm{L}$ & 7.000 \\
\hline & NEUT\% & Ratio of neutrophil & 0.647 & & & 0.647 \\
\hline & LYMPH\% & Ratio of lymphocyte & 0.286 & & & 0.286 \\
\hline & MONO\% & Ratio of monocytes & 0.044 & & & 0.044 \\
\hline & $\mathrm{EO} \%$ & Ratio of eosinophils & 0.013 & & & 0.013 \\
\hline & $\mathrm{BASO} \%$ & Ratio of basophils & 0.006 & & & 0.006 \\
\hline & IG\% & $\begin{array}{l}\text { Ratio of immature } \\
\text { granulocytes }\end{array}$ & 0.004 & & & 0.004 \\
\hline & YC1 & Annormal lymphocytes & Not found & & & 0 \\
\hline & YZXB5 & Juvenile cells & Not found & & & 0 \\
\hline & NEUT\# & Neutrophil count & 4.529 & & $\times 10 \wedge 9 / L$ & 4.529 \\
\hline & LYMPH\# & Lymphocyte count & 2.002 & & $\times 10 \wedge 9 / L$ & 2.002 \\
\hline & MONO\# & monocyte count & 0.308 & & $\times 10 \wedge 9 / L$ & 0.308 \\
\hline & EO\# & eosinophil count & 0.091 & & $\times 10 \wedge 9 / L$ & 0.091 \\
\hline & BASO\# & Basophil count & 0.042 & & $\times 10 \wedge 9 / L$ & 0.042 \\
\hline & IG\# & $\begin{array}{l}\text { immature granulocyte } \\
\text { count }\end{array}$ & 0.028 & & $\times 10 \wedge 9 / L$ & 0.028 \\
\hline & $H G B$ & Hemoglobin & 148 & $120 \sim 160$ & $g / L$ & 148.000 \\
\hline
\end{tabular}


Table 1 Laboratory results including routine blood work, antinuclear antibody analysis, thyroid tests, and hepatic and renal functions (Continued)

\begin{tabular}{|c|c|c|c|c|c|c|}
\hline & RBC & Erythrocyte count & 4.88 & $4 \sim 5.5$ & $\times 10 \wedge 12 / L$ & 4.880 \\
\hline & $\mathrm{HCT}$ & Hematokrit & 0.429 & $0.4 \sim 0.54$ & & 0.429 \\
\hline & MCV & $\begin{array}{l}\text { Mean corpuscular } \\
\text { volume }\end{array}$ & 87.90 & $80 \sim 100$ & $\mathrm{fl}$ & 87.900 \\
\hline & $\mathrm{MCH}$ & $\begin{array}{l}\text { Mean corpuscular } \\
\text { hemoglobin }\end{array}$ & 30.30 & $27 \sim 34$ & $\mathrm{pg}$ & 30.300 \\
\hline & $\mathrm{MCHC}$ & $\begin{array}{l}\text { Mean corpuscular- } \\
\text { hemoglobin concentration }\end{array}$ & 345 & $320 \sim 360$ & $g / L$ & 345.000 \\
\hline & RDW-CV & $\begin{array}{l}\text { Red cell distribution } \\
\text { width-CV }\end{array}$ & 13.0 & $11.6 \sim 14.6$ & $\%$ & 13.000 \\
\hline & RDW-SD & $\begin{array}{l}\text { Red cell distribution } \\
\text { width-SD }\end{array}$ & 41.5 & & $\mathrm{fl}$ & 41.500 \\
\hline & PLT & platelets counts & 334 & $100 \sim 300$ & $\times 10 \wedge 9 / L$ & 334.000 \\
\hline & $\mathrm{PCT}$ & Thrombocytocrit & 0.34 & $0.11 \sim 0.28$ & & 0.340 \\
\hline & MPV & Mean platelet volume & 10.30 & $6.5 \sim 11$ & $\mathrm{fl}$ & 10.300 \\
\hline & P-LCR & Platelet-large cell ratio & 27.40 & & $\%$ & 27.400 \\
\hline & PDW & Platelet distribution width & 12.30 & $9 \sim 17$ & $\%$ & 12.300 \\
\hline & ZDKL & Toxic granulation & Negative & & & 0 \\
\hline & $\mathrm{YHH}$ & $\begin{array}{l}\text { Nucleated red blood cell } \\
\text { count }\end{array}$ & 0.0 & & $/ 100 W B C$ & 0 \\
\hline & YCC & Abnormal cell & Not found & & & 0 \\
\hline & BBBC & Sample preservation & $\begin{array}{l}\text { The sample retained } \\
\text { for three days }\end{array}$ & & & 1.000 \\
\hline \multirow[t]{2}{*}{ Blood type } & $A B O$ & ABO blood group system & $A B$ & & & 0 \\
\hline & $\mathrm{RH}$ & $\mathrm{RH}(\mathrm{D})$ blood group & Positive & & & 0 \\
\hline \multirow[t]{5}{*}{ Thyroid function tests } & TOTT3 & Total T3 & 0.78 & $0.87 \sim 1.78$ & $\mathrm{ng} / \mathrm{ml}$ & 0.780 \\
\hline & TOTT4 & Total T4 & 7.01 & $6.10-12.20$ & $\mu \mathrm{g} / \mathrm{dl}$ & 7.010 \\
\hline & FT3 & Free T3 & 2.52 & $2.50 \sim 3.90$ & $\mathrm{pg} / \mathrm{ml}$ & 2.520 \\
\hline & FRT4 & Free T4 & 0.88 & $0.61 \sim 1.12$ & $\mathrm{ng} / \mathrm{dl}$ & 0.880 \\
\hline & TSH & $\begin{array}{l}\text { Thyroid stimulating } \\
\text { hormone }\end{array}$ & 1.06 & $0.34 \sim 5.60$ & $\mu \mathrm{lU} / \mathrm{ml}$ & 1.060 \\
\hline \multirow[t]{2}{*}{ Bronchofiberscope } & & Mould & Not found & & & 0 \\
\hline & & Smear results & $\begin{array}{l}\text { Found no acid fast } \\
\text { bacilli }\end{array}$ & & & 0 \\
\hline
\end{tabular}

months after the botulinum toxin injections, the palatal tremors recurred; but the frequency of the tremors and number of attacks were reduced. Rapid contractions of the velar muscles sometimes occurred when he was nervous or tired, or had consumed alcohol; but he could control them voluntarily (Additional file 5: Video S5). An EMG test at this point showed complete relief of the LVP and uvularis muscles besides palatoglossus and palatopharyngeus.

\section{Discussion}

Auditory clicks arising from the rhythmic contraction of any of the muscles in the ear and throat $[1,2]$ are regarded as a primary symptom of EPT. The case of our patient was unique, because the clicks were nasal in origin.

The tremors would stop when the patient was asleep. The palatal tremor cycle could not be restored by inhibition of the trigeminal nerve using lidocaine. Neurological examination results and brain MRI scans were normal. MRI scans have shown increased signal intensity on T2 weighted images in SPT patients with injury to the dentate-olivary complex, indicating hypertrophy of the olivary nucleus $[7,8]$. MRI scans of our patient revealed no evidence of structural abnormalities. Thus, SPT was excluded as a cause. To our knowledge, this is the first case of EPT associated with nasal clicks instead of otic clicks. 


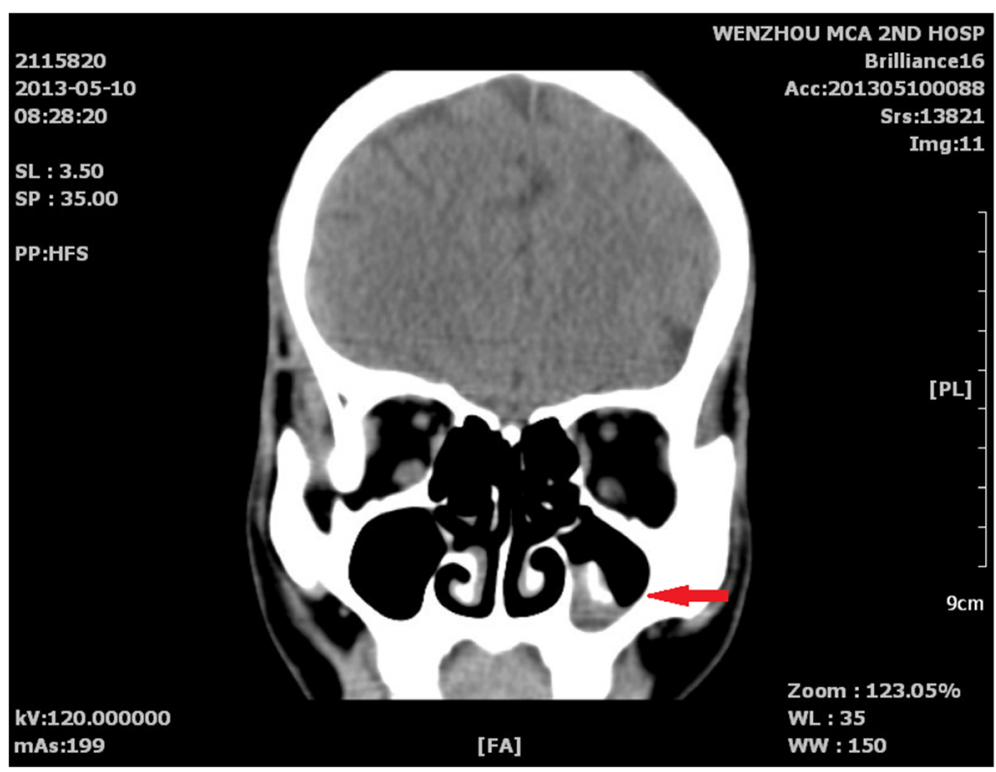

Fig. 1 Coronal CT image of sinuses, indicating fungal rhinosinusitis of the left maxillary sinus

Otic clicks are caused by abnormal contractions of both the TVP and LVP muscles. However, objective otic clicks due to LVP contractions have not been reported since 1996 [9]. In our patient, otic clicks were completely absent (Additional file 1: Video S1). Therefore, we suspected that some muscles of the soft palate other than the TVP such as the palatopharyngeus, palatoglossus, uvularis, and/or LVP muscles contributed to the nasal clicks. EMG results confirmed that all the above muscles were involved, except the TVP.
EPT clicks are affected by mouth opening, speaking [9], head position [10] and relaxation [11]. In our patient, tilting the head backwards and speaking could completely suppress the tremors.

No specific treatment has been reported for EPT. In 1997, Cakmur et al. [12] reported that a 16-year old girl, who had been diagnosed with EPT at the age of six, was successfully treated with flunarizine, which is a selective calcium entry blocker with antihistaminic, antiserotoninergic and antidopaminergic activity [13]. However, the



Fig. 2 Cranial MRI image of the horizontal position. No occupying lesions or abnormal signal of the inferior olive was observed 

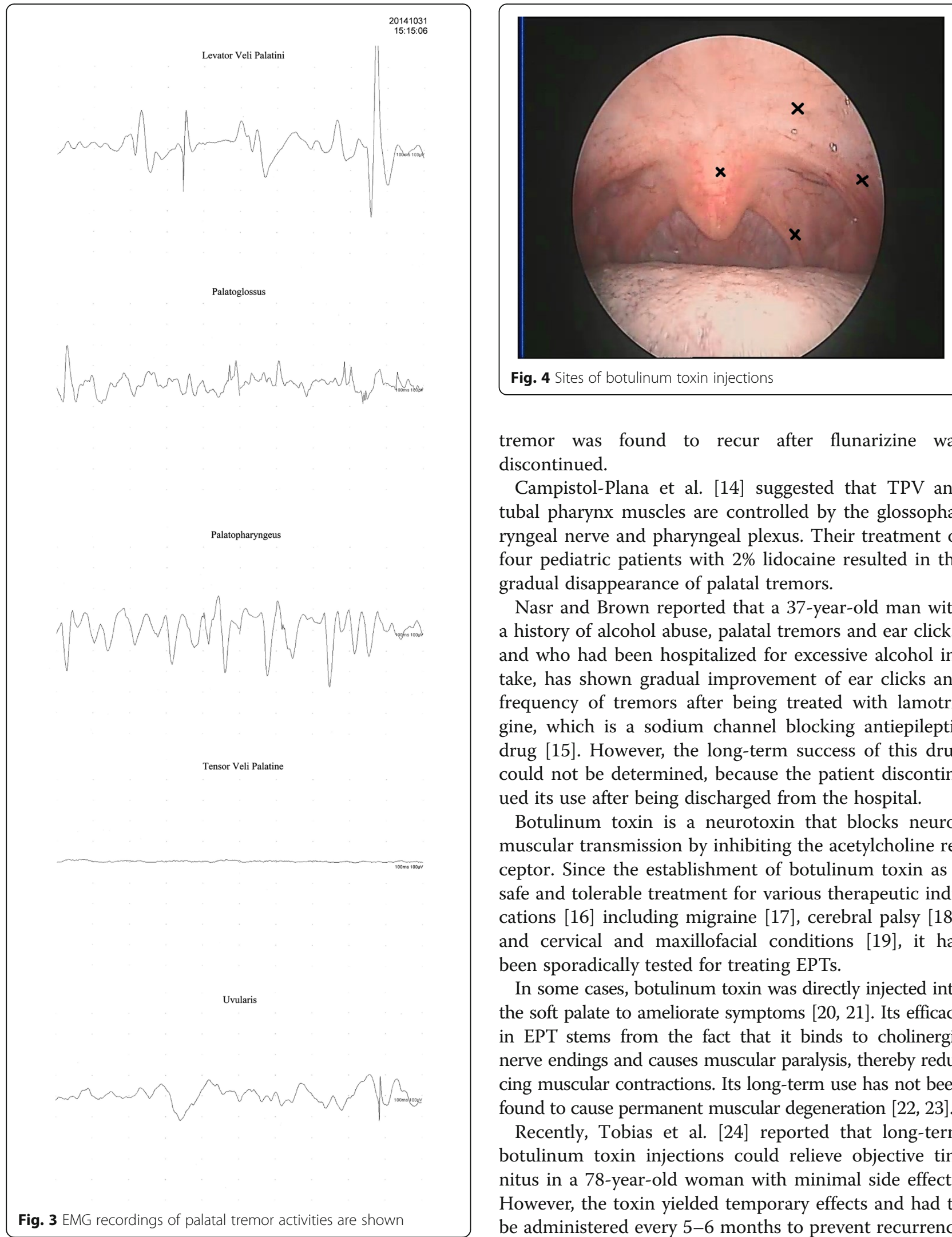

Fig. 4 Sites of botulinum toxin injections

tremor was found to recur after flunarizine was discontinued.

Campistol-Plana et al. [14] suggested that TPV and tubal pharynx muscles are controlled by the glossopharyngeal nerve and pharyngeal plexus. Their treatment of four pediatric patients with $2 \%$ lidocaine resulted in the gradual disappearance of palatal tremors.

Nasr and Brown reported that a 37-year-old man with a history of alcohol abuse, palatal tremors and ear clicks, and who had been hospitalized for excessive alcohol intake, has shown gradual improvement of ear clicks and frequency of tremors after being treated with lamotrigine, which is a sodium channel blocking antiepileptic drug [15]. However, the long-term success of this drug could not be determined, because the patient discontinued its use after being discharged from the hospital.

Botulinum toxin is a neurotoxin that blocks neuromuscular transmission by inhibiting the acetylcholine receptor. Since the establishment of botulinum toxin as a safe and tolerable treatment for various therapeutic indications [16] including migraine [17], cerebral palsy [18], and cervical and maxillofacial conditions [19], it has been sporadically tested for treating EPTs.

In some cases, botulinum toxin was directly injected into the soft palate to ameliorate symptoms [20, 21]. Its efficacy in EPT stems from the fact that it binds to cholinergic nerve endings and causes muscular paralysis, thereby reducing muscular contractions. Its long-term use has not been found to cause permanent muscular degeneration [22, 23].

Recently, Tobias et al. [24] reported that long-term botulinum toxin injections could relieve objective tinnitus in a 78-year-old woman with minimal side effects. However, the toxin yielded temporary effects and had to be administered every 5-6 months to prevent recurrence of symptoms that could affect the daily activities of the patient. 
Anis and Pollak reported that a 36-year-old woman with EPT, who had failed to respond to conservative treatment with anxiolytics, was successfully treated with 2-3 injections of botulinum toxin [25]. Symptomatic relief was obtained within two days of injection.

Even though the source of the clicks in our patient was different from that reported in previous cases, we applied symptom-guided injections of botulinum toxin in our patient. Unlike the temporary relief provided by lidocaine injections, four simultaneous injections of botulinum toxin were found to diminish the tremors in our patient. Although our patient tolerated the treatment well, alleviation of symptoms required at least two weeks. Variability in time and dosage required for symptomatic relief in our patient and in patients reported in previous studies suggests that individualized titration of dose and frequency by close monitoring of symptoms may be critical in achieving long-term benefits, as suggested by Anis and Pollak [25].

Although the etiology of EPT remains unclear, some patients were found to have minor ailments [26] or symptoms such as otitis media, fever, or tonsillitis before the occurrence of EPTs. Our patient had excessive phlegm for two years and pharyngalgia for one week. We believe that these symptoms could be related to the etiology of EPT, because they were spontaneously relieved within 15 days after botulinum toxin treatment. Additional studies will be required to determine the pathogenesis of EPT with nasal clicks, as well as the occurrence of phlegm and pharyngalgia.

\section{Conclusions}

Tinnitus is the most common symptom of EPT. In this study, we report the first case of a patient with EPT who presented with nasal clicks, instead of objective pulsatile tinnitus. Similar to previous reports, botulinum toxin injections were found to alleviate symptoms and improve the quality of life of the patient for up to three months. Although the detailed pathophysiology and etiology of EPT that presented with nasal clicks remains unclear, we recommend that otolaryngologists should expect this rare occurrence in the clinical setting. Patients with this rare disorder usually have a poor social life. Therefore,

\section{Additional files}

Additional file 1: Video S1. "Clicking" noise and video recorded by
cellphone. (MP4 $1840 \mathrm{~kb}$ )
Additional file 2: Video S2. Oropharyngeal examination video
recorded by endoscopy. (MP4 $1700 \mathrm{~kb}$ )
Additional file 3: Video S3. Nasopharyngeal examination video
recorded by endoscopy. (MP4 $7560 \mathrm{~kb}$ )
Additional file 4: Video S4. Tremor ceased when tilted backward.
(MP4 $6310 \mathrm{~kb}$ )
Additional file 5: Video S5. Endoscopic record 8 months after injection.
(MP4 $22200 \mathrm{~kb})$

clinicians should exercise care, patience and attention when handling such cases in order not to worsen the psychological status of the patient.

\section{Abbreviations \\ CT: Computed tomography; EMG: Electromyography; EPT: Essential palatal tremor; LVP: Levator veli palatini; MRI: Magnetic resonance imaging; SPT: Symptomatic palatal tremor; TVP: Tensor veli palatini}

\section{Acknowledgements}

Not applicable.

Funding

Not applicable.

Availability of data and materials

The data and materials supporting the conclusions of this article are included within the article and its additional files.

\section{Authors' contributions}

LN conceived of the study, participated in its design and coordination and helped to draft the manuscript. YY drafted the article and revising it critically for important intellectual content. SL participated in the EMG data. BL participated in the endoscopic data. All authors read and approved the final manuscript.

\section{Competing interests}

The authors declare that they have no competing interests.

\section{Consent for publication}

The participant in this report signed the consent for publication of his personal data in any form (including individual details, images or videos) in this article.

\section{Ethics approval and consent to participate}

The participant in this report signed informed consent, participated voluntarily, and had the right to withdraw at any stage. Ethical approval was obtained from The Second Hospital of Wenzhou Medical University Research Ethics Committee. The ethics reference number is L-2016-17.

Received: 30 August 2016 Accepted: 1 November 2016

Published online: 22 November 2016

\section{References}

1. Zadikoff C, Lang AE, Klein C. The 'essentials' of essential palatal tremor: a reappraisal of the nosology. Brain. 2006;129:832-40.

2. Carman KB, Ozkan S, Yarar C, Yakut A. Essential palatal tremor treated with botulinum toxin. Pediatr Neurol. 2013;48:415-7.

3. Deuschl G, Mischke G, Schenck E, Schulte-Monting J, Liicking $\mathrm{CH}$. Symptomatic and essential rhythmic palatal myoclonus. Brain. 1990;113:1645-72.

4. Deuschl G, Toro C, Valls-Sole J, Zeffiro T, Zee DS, Hallett M. Symptomatic and essential palatal tremor. Clinical, physiological and MRI analysis. Brain. 1994;3(17):775-88.

5. Chung EJ, Jung H, Kima SJ. A case of intractable psychogenic essential palatal tremor. J Mov Disord. 2012;5(2):55-6.

6. Margari F, Giannella G, Lecce PA, Fanizzi P, Toto M, Margari L. A childhood case of symptomatic essential and psychogenic palatal tremor. Neuropsychiatr Dis Treat. 2011;7:223-7.

7. Zan K, Li X, Zu J, et al. Clinical manifestations and MR imaging characteristics of hypertrophic olivary degeneration. Chin J Neuromed. 2013;9:953-5 [In Chinese].

8. Kitajima M, Korogi Y, Shimomura O, Sakamoto Y, Hirai T, Miyayama H, Takahashi M. Hypertrophic olivary degeneration: MR imaging and pathologic findings. Radiology. 1994;192:539-42.

9. Morini A, Boninsegna C, Nostro M, Simonetti S, Orrico D, Moretto G, Tinazzi M. Palatal tremor suppressed by mouth opening clinical and neurophysiological correlations in two patients. J Neurol. 2005;252:1335-40.

10. Tomkinson A, Craven C, Brown MJ. Palatal myoclonus affected by neck position. J Laryngol Otol. 1995;109:61-2. 
11. Soso MJ, Nielsen VK, Jannetta PJ. Palatal myoclonus. Reflex activation of contractions. Arch Neurol. 1984;41:866-9.

12. Cakmur R, Idiman E, Idiman F, Baklan B, Ozkiziltan S. Essential palatal tremor successfully treated with flunarizine. Eur Neurol. 1997;38:133-4.

13. Llinas R, Yarom Y. Oscillatory properties of guinea-pig inferior olivary neurons and their pharmacological modulation: an in vitro study. J Physiol Lond. 1986;376:163-82.

14. Campistol-Plana J, Majumdar A, Fernández-Alvarez E. Palatal tremor in childhood: clinical and therapeutic considerations. Dev Med Child Neurol. 2006; $48: 982-4$

15. Nasr A, Brown N. Palatal myoclonus responding to lamotrigine. Seizure. 2002;11:136-7

16. Naumann M, Jankovic J. Safety of botulinum toxin type A: a systematic review and meta-analysis. Curr Med Res Opin. 2004;20:981-90.

17. Troost BT. Botulinum toxin type $A$ (Botox) in the treatment of migraine and other headaches. Expert Rev Neurother. 2004;4(1):27-31.

18. Lukban MB, Rosales RL, Dressler D. Effectiveness of botulinum toxin A for upper and lower limb spasticity in children with cerebral palsy: a summary of evidence. J Neural Transm. 2009;116(3):319-31.

19. Inde SK, Konstantinovic VS. The therapeutic use of botulinum toxin in cervical and maxillofacial conditions: an evidence-based review. Oral Surg Oral Med Oral Pathol Oral Radiol Endod. 2007:104(2):e1-11.

20. Kutukcu Y, Imirzalioglu N, Odabasi Z. Essential palatal myoclonus in monozygotic male twins. J Neurol. 2003;250:885-6.

21. Jero J, Salmi T. Palatal myoclonus and clicking tinnitus in a 12-year-old girlcase report. Acta Otol. 2000;543:61-2.

22. Penney SE, Bruce IA, Saeed SR. Botulinum toxin is effective and safe for palatal tremor: a report of five cases and a review of the literature. J Neurol. 2006;253:857-60

23. Stidham KR, Solomon PH, Roberson JB. Evaluation of botulinum toxin A in treatment of tinnitus. Otolaryngol Head Neck Surg. 2005;132:883-9.

24. Conill Tobías N, de Paula VC, García Callejo FJ, Marco AJ. Objective tinnitus from palatal myoclonus. Use of botulinum toxin: a case report. Acta Otorrinolaringol Esp. 2012;63(5):391-2.

25. Anis MM, Pollak N. Treatment of Palatal Myoclonus with Botulinum Toxin Injection. Case Rep Otolaryngol. 2013. doi: 10.1155/2013/231505.

26. Samuel M, Kleiner-Fisman G, Lang AE. Voluntary control and a wider clinical spectrum of essential palatal tremor. Mov Disorders. 2004;19:717-9.

\section{Submit your next manuscript to BioMed Central and we will help you at every step:}

- We accept pre-submission inquiries

- Our selector tool helps you to find the most relevant journal

- We provide round the clock customer support

- Convenient online submission

- Thorough peer review

- Inclusion in PubMed and all major indexing services

- Maximum visibility for your research

Submit your manuscript at www.biomedcentral.com/submit

) Biomed Central 